\title{
O PAPEL DA "CIVILIZAÇÃO ECOLÓGICA" CHINESA NA NOVA ORDEM AMBIENTAL INTERNACIONAL: IDEIAS PARA UM MUNDO PÓS-COVID
}

\author{
Niklas Werner Weins ${ }^{1}$ \\ Leila da Costa Ferreira ${ }^{2}$ \\ Rita de Cassia Oliveira Feodrippe ${ }^{3}$
}

Resumo: A Construção de uma Civilização Ecológica responde à grave crise ambiental na China e está começando a causar mudanças de paradigma na política ambiental doméstica. No decorrer da pandemia da Covid-19, ficou evidente a ambição geopolítica e importância do país como poder normativo em questões da governança global. Utilizando-se a teoria construtivista, analisa-se a atuação de Pequim em instituições, o estabelecimento de normas nacionais e seu potencial para redefinir a ordem ambiental global. Discutem-se a atuação chinesa em organizações internacionais e eco-compensações para indicar possíveis comportamentos futuros do país na definição de agendas ambientais. Concluímos que a China contribui com visões normativas na área ambiental, principalmente nos países do Sul Global.

Palavras-chave: Sociologia ambiental. Instituições. Normas. Compensações ecológicas.

\section{THE ROLE OF THE CHINESE "ECOLOGICAL CIVILIZATION" IN THE NEW INTERNATIONAL ENVIRONMENTAL ORDER: IDEAS FOR A POST-COVID WORLD}

Abstract: The Construction of an Ecological Civilization responds to the serious environmental crisis in China and is already beginning to cause paradigm shifts in domestic environmental policies. During the Covid-19 pandemic, the country's geopolitical ambition and importance as a normative power in global governance issues became ever more evident. Through constructivist theory, we analyze Beijing's role in institutions, national norm-setting and its potential to redefine the global environmental order. The Chinese participation in international organizations and eco-compensations are discussed to indicate possible future efforts in the definition of environmental agendas. We conclude that China already contributes normatively to the environmental area, especially in countries of the Global South.

\footnotetext{
1 Universidade Estadual de Campinas, Instituto de Filosofia e Ciências Humanas, Campinas, Brasil,weinsniklas@gmail.com, https://orcid.org/0000-0003-1345-6720

2 Universidade Estadual de Campinas, Núcleo de Estudos e Pesquisas Ambientais / Instituto de Filosofia e Ciências Humanas, Campinas, Brasil, leilacf@unicamp.br, https://orcid.org/00000003-4138-9860

${ }^{3}$ Escola de Guerra Naval, Programa de Pós-Graduação em Estudos Marítimos, Rio de Janeiro, Brasil, ritafeodrippe@gmail.com, https://orcid.org/0000-0002-8607-1162
} 
Keywords: Environmental sociology. Institutions. Norms. Ecological compensations.

\section{EL PAPEL DE LA "CIVILIZACIÓN ECOLÓGICA" CHINA EN EL NUEVO ORDEN AMBIENTAL INTERNACIONAL: IDEAS PARA UN MUNDO PÓS- COVID}

Resumen: La Construcción de una Civilización Ecológica responde a la grave crisis ambiental de China y ya está empezando a producir cambios de paradigma en las políticas ambientales nacionales. Durante la pandemia de Covid-19, la ambición geopolítica del país y su importancia como potencia normativa en la gobernanza global se hicieron evidentes. A través de la teoría constructivista, analizamos el papel de Beijing en las instituciones, el establecimiento de normas nacionales y su potencial para redefinir el orden ambiental mundial. Se examina la participación en organizaciones internacionales y las eco-compensaciones para indicar posibles esfuerzos futuros en la definición de agendas ambientales. Se señala que China contribuye normas al ámbito ambiental, especialmente en los países del Sur global.

Palabras clave: Sociología ambiental. Instituciones. Normas. Compensaciones ecológicas.

\section{Introdução}

A discussão sobre o sistema internacional no início do século $\mathrm{XXI}$ é guiada por várias perguntas essenciais sobre o futuro de sua ordem, e a questão ambiental é, certamente, uma das temáticas globais decisivas (RIBEIRO, 2001; GIDDENS, 2009; FERREIRA, 2017). Adicionalmente, a ascensão da República Popular da China (RPC) como poder global nesta discussão, sem dúvida, será o evento que mais potencial possui para moldar a política internacional (MINZER, 2007). Entre muitas áreas de crescente atuação, a China também tem estado envolvida ativamente no debate internacional sobre a questão climática (HART, 2019). Desde o estabelecimento da Convenção-Quadro das Nações Unidas sobre Mudança do Clima (UNFCCC, na sigla em inglês) em 1992, no Rio de Janeiro, a RPC foi o primeiro país do mundo a ratificar a Convenção, fornecendo estruturas institucionais e assinando tratados internacionais relevantes (BARBI et al., 2016). No entanto, naquela época, quinze anos depois do início das políticas de Reforma e Abertura (gaige kaifang 改革开放), as intenções do 
governo chinês começaram a conflitar com as aspirações internacionais, não permitindo que as políticas globais reduzissem a taxa de crescimento econômico do país (ZAGO, 2017). Sendo o maior emissor mundial de gases de efeito estufa, responsável por mais de um terço das emissões globais em 2014, a China hoje é um ator fundamental na mitigação das mudanças climáticas globais, com um papel proeminente e ativo na Organização das Nações Unidas (BARBI et al., 2016). Porém, desde o início da pandemia da Covid-19 em 2020, o país parece estar atuando de forma mais decisiva no sistema internacional (GROSSMAN, 2020; JONES, 2020). Tal realidade orienta a análise construtivista deste artigo sobre a atuação chinesa na arena ambiental internacional para avaliar o quanto ela está contribuindo para a criação de novas normas. As reflexões aqui apresentadas se fundamentam em pesquisas anteriores à pandemia e, enquanto ela ainda se desdobra, devemos ficar cautelosos quanto a quaisquer possíveis conclusões (LAHIRI-DUTT, 2020).

Neste trabalho, propomos uma discussão sobre as implicações da "Civilização Ecológica Socialista Chinesa" (Zhongguo tese shehui zhuyi shengtai wenming 中国社会主义生态文明) e as normas que sua aplicação está começando a estabelecer em instituições internacionais, a partir do desenho de diretrizes centrais para um modelo próprio de desenvolvimento chinês (WEINS, 2015; SCHMITT, 2016; CHEN, 2018) - o que se torna cada vez mais nítido durante a pandemia da Covid-19. Por meio da Civilização Ecológica (CE), juntamente com outra políticas, a República Popular está apresentando um "modelo alternativo não democrático de adaptação ambiental" (BEESON, 2018, p. 38) que, sendo bem sucedido, pode ser tolerado inclusive por outros atores no sistema internacional, que são capazes de aceitar ou até mesmo usar tal exemplo como norma para justificar abordagens não democráticas à governança ambiental. Bell (2015, p. 36) acrescenta que "se a China continuar a 'meritocratizar' [suas instituições de governo] e evitar a má formulação política decorrente da ignorância dos eleitores em países democráticos (...), ela estabelecerá um modelo para os outros." Essas ideias são relevantes no início do que nomeamos Antropoceno, em que os desafios e riscos no enfrentamento 
da crise ambiental se mostram cada vez mais evidentes (FERREIRA; BARBI, 2016; HANSON, 2019), como ocorre com a pandemia da Covid-19.

\section{Normas na política internacional}

A ascensão da China tem sido tratada em numerosas análises pelas escolas neorrealistas e neoliberais das Relações Internacionais. O país tem sido identificado como "potência emergente", uma "ameaça a uma ordem global liderada pelo Ocidente", ou como um "grande competidor" na esfera econômica (EBERHARD, 2008; JONES, 2020). No entanto, poucas análises empregam abordagens não-racionalistas como o construtivismo, cujo enfoque em variáveis para além da maquinaria militar e a atuação econômica permite a interpretação de uma gama mais ampla de temas, no mais longo prazo. O construtivismo social, ao contrário do neorrealismo ou do neoliberalismo, questiona alguns pressupostos básicos sobre a natureza humana entendida como base destas teorias. Glosny (2010: p. 103) sugere que o construtivismo social tem um poder explicativo mais conciso para um fenômeno como a atual mudança na ordem global e o comportamento da China nas organizações internacionais. No centro da discussão estão as normas, comumente entendidas como "expectativas compartilhadas de comportamento que conotam o que é considerado culturalmente desejável e apropriado" (MARSHALL; SCOTT 2009, p. 519).

Adotamos a abordagem construtivista, entendendo sua importância para analisar comportamentos, em particular no enfrentamento de grandes incertezas como a pandemia da Covid-19. Mais amplamente, os desafios relacionados com a busca da sustentabilidade precisam considerar que os atores principais não são somente os Estados, mas agentes múltiplos sobrepostos que fazem parte da geopolítica na construção de normas, identidades e ideais de desenvolvimento de países e suas sociedades modernas complexas (HAAS, 1992; RIBEIRO, 2001; FERREIRA, 2017).

Uma das ideias fundamentais do construtivismo é a de que os atores e a estrutura se constituem mutuamente. As regras de conduta são constituídas pelos atores e, ao mesmo tempo, reproduzidas e portanto mantidas por eles, o 
que podemos chamar de constituição mútua de agente e estrutura (intersubjetiva) (AUTH, 2015, p. 193). Na literatura sociológica das relações internacionais, fala-se em "co-construção" da realidade. A teoria construtivista consegue explicar por que os Estados se envolvem em certos padrões duradouros e por que mudam seus comportamentos e normas diante de uma dada situação (AUTH, 2015).

A estrutura do sistema internacional consiste em conhecimentos e percepções intersubjetivamente compartilhados, os chamados "conhecimentos coletivos" (WENDT, 1992). Sob a influência da interação com outros, os Estados mudam constantemente suas identidades e interesses (COPELAND, 2000), de forma que essas mudanças contínuas levam a uma consequente "transformação contínua do sistema todo" (WENDT, 1992, p. 393). A mudança ocorrida em um ou vários atores pode criar novas expectativas sobre os papéis de outros, que passam a decorrer de mudanças nas visões normativas, nos processos evolutivos de aprendizagem e no questionamento crítico do "eu". Estes movimentos acabam por levar a uma compreensão diferente dos papéis e identidades dos outros Estados (WENDT, 1992, p. 419).

De acordo com a teoria construtivista, a mudança de visões normativas ocorre em três fases. Primeiramente (1), uma nova norma desejada é definida e emerge no sistema, para depois ser internalizada (2). Como terceiro e último passo (3), ocorrem efeitos de socialização e aprendizado que universalizam a norma (WENDT, 1992, p. 413). Finnemore e Sikink (1998, p. 895) acrescentam a fase da cascata de norma ("ponto de inflexão") à parte de difusão da norma (veja Figura 1), e afirmam que esse padrão do ciclo de vida de normas está empiricamente confirmado.

Figura 1- Ciclo de vida de normas

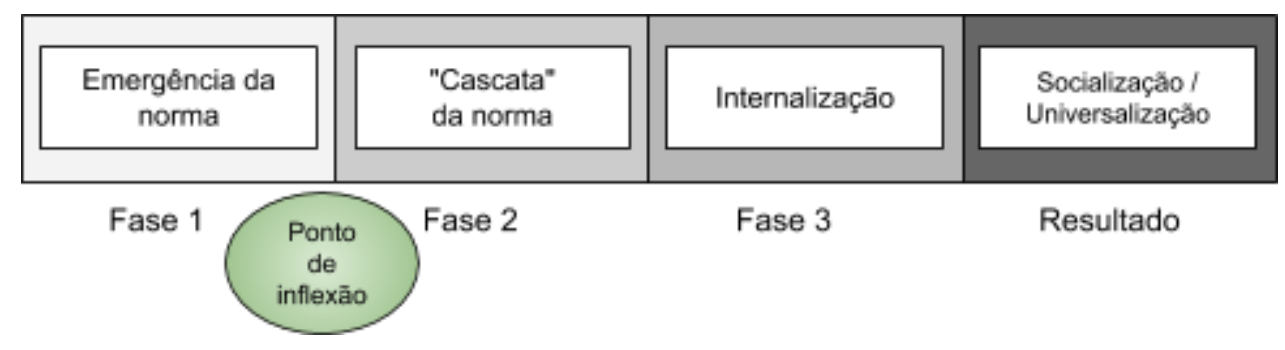


Adaptado de Finnemore e Sikkink, 1998.

Um exemplo clássico é o do surgimento da soberania como uma nova norma na Europa medieval, quando uma dissociação de intervenções religiosas motivadas ocorreu através de um processo comparável (AUTH, 2015). Depois de que a norma desejável (soberania) foi bem definida, ela se internalizou em diferentes Estados. A nova percepção da realidade pode eventualmente ser vista como característica própria e estável do "eu" de um número crescente de Estados. A última fase do questionamento crítico proposto por Wendt implica o abandono do entendimento anterior. Um Estado avalia os benefícios da nova normatividade e os custos de abandonar a antiga (AUTH, 2015). Se esse processo levar a uma decisão positiva para uma mudança de papel, podemos falar da ocorrência de um distanciamento gradual do antigo papel e da identidade.

Como exemplos atuais desse processo, pode-se citar: um menor desempenho econômico, no caso do desenvolvimento sustentável, ou; um papel mais ou menos ativo do Estado no caso do combate à Covid-19. Já que a visão de mundo atual não pode ser mais aceita, uma avaliação de premissas que constituiam a percepção anterior da realidade deve acontecer, para que, então, um novo "eu" alterado possa ser mostrado na apresentação externa dos países, - que por fim marca o início de uma nova prática. A nova identidade, consequentemente, torna-se a base para a política externa de um Estado. Essa mudança é necessária devido a uma mudança anterior gerada por parte de outros, o que leva a um questionamento da própria identidade do país.

$\mathrm{Na}$ discussão sobre o papel de comunidades epistêmicas que formulam e interpretam fatos técnicos, Haas (1992, p. 15) expõe que a "elucidação das relações de causa e efeito dos problemas pode de fato levar à redefinição de interesses pré-concebidos ou à identificação de novos interesses". Tal mudança nas comunidades epistêmicas já está começando a se evidenciar com a ascensão da China, cuja efetivação está ocasionando o aparecimento de novos assuntos e olhares nos "mapas" da ciência global (MASOOD, 2019). 


\section{O início da Construção de uma Civilização Ecológica}

Tais considerações teóricas são de alta relevância, uma vez que consideramos as expectativas da atuação chinesa no mundo pós-pandêmico e suas consequências para a sociedade internacional. Nesta seção, focamos na dimensão ambiental e discutimos a mudança do paradigma do Partido Comunista Chinês (PCC) acerca da política industrial desenvolvimentista dos anos 1980 de crescimento a todo custo para a "Construção de uma CE" no ano 2007. Em combinação com a continuação de um modelo autoritário, alguns autores chamam o modelo chinês de "autoritarismo ambiental" (EATON; KOSTKA, 2014). Portanto, esse modelo de governança pode desempenhar um papel importante na explicação da geopolítica chinesa e do (re)ordenamento do sistema internacional (BEESON, 2018). As mudanças relacionadas com o multilateralismo chinês nos últimos 30 anos podem ser um bom exemplo dessas expectativas e das recentes mudanças do papel chinês na governança ambiental global (CHAN et al., 2011), considerando o país como um agente "empreendedor de normas" (GOTTWALD; DUGGAN, 2011; WEINS, 2015).

O modelo de desenvolvimento industrial seguido pela China desde a "Abertura e Reforma" (gaige kaifang 改革开放) sob o Pensamento de Deng Xiaoping (邓小平), após a época maoísta (Figura 2), gerou um crescimento econômico inédito na história humana. As quatro modernizações de Deng nas áreas de agricultura, indústria, defesa, e ciência e tecnologia foram seguidas por uma forte urbanização e pela transformação da economia às custas do meio ambiente, o qual sofreu danos irreparáveis e acumulou um número de riscos ambientais (ZAGO, 2017). A seguir, discutimos resumidamente a ascensão da China e sua recente virada para políticas econômicas mais orientadas por variáveis ambientais. 
Figura 2- Ideologias que guiaram os líderes na República Popular da China de 1949 até hoje.

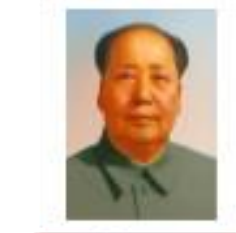

Mao Zedong

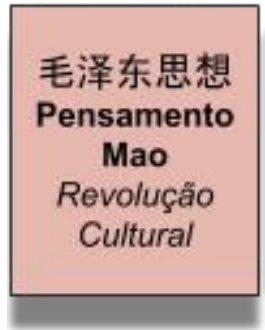

1949

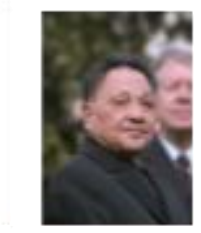

Deng Xiaoping

邓小平思想 Pensamento Deng Reforma e Abertura

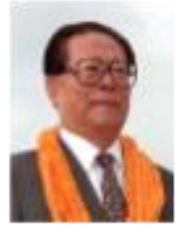

Jiang Zemin

中国特色社会主义 I三个代表

Socialismo com caracteristicas chinesas / Tripla Representatividade

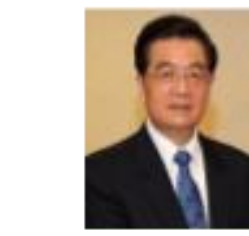

Hu Jintao

和谐社会 科学发展观 Sociedade Harmônica Desenvolvimento Cientifico
Xi Jinping

中国梦 美丽中国 / 生态文明 Sonho chinês Beautiful China / Civilização Ecológica

As origens técnicas da CE, de acordo com Schmitt (2016) e Marinelli (2018), encontram-se nos anos 1980. A nova norma surgida no movimento da agricultura ecológica foi posteriormente adotada em nível nacional, influenciando os conceitos políticos do PCC a partir da Tripla Representatividade e da Sociedade Harmônica (Figura 2). Enquanto as discussões em nível internacional estavam convergindo para cunhar a norma do "desenvolvimento sustentável", a industrialização e a revolução verde estavam ainda em pleno processo em muitos países do Sul Global.

Porém, quando muito se focava no papel preponderante da economia em uma suposta dicotomia humano-natureza no pensamento hegemônico ocidental, a cultura do capitalismo pregava valores que iam na contramão desse pensamento compartimentado. De acordo com Pan (2006, p. 17) "o Ocidente perdeu a oportunidade de desenvolver uma Civilização Ecológica" devido ao foco que deu à integração de soluções de mercado e sustentabilidade, deixando de lado mudanças culturais. Essa "oportunidade perdida para o Ocidente proporcionou à nação chinesa a oportunidade de um estilo de desenvolvimento transcendente" (ibid.). A análise do autor sugere uma evolução da civilização 
tradicional para uma civilização industrial e posteriormente para a CE, que se está construindo tanto com base em valores tradicionais confucionistas e taoistas, quanto nas teorias de Marx e Engels, construindo uma ponte importante para a legitimação do regime do PCC.

A crescente autoconfiança da China na arena internacional no início do século XXI se manifesta, por exemplo, na declaração do Sonho Chinês, do qual a Construção de uma CE faz parte integral (Figura 2). O presidente Xi Jinping (习近平) contesta abertamente modelos ocidentais, como o Consenso de Washington, e mostra mudanças significativas enquanto à identidade chinesa, que está associada a um país o qual está definindo seu próprio caminho e normas diferenciadas (GOTTWALD; DUGGAN, 2011; BELL, 2015). A defesa de novas normas de política externa já se expressa, por exemplo, em assuntos de defesa e segurança na atuação chinesa na Organização para Cooperação de Xangai. O lema de Deng Xiaoping era "manter um perfil baixo e esperar seu tempo" (taoguang yanghui 韬光养晦), o que tem mudado, desde que Xi Jinping assumiu, para uma atuação cada vez mais assertiva e ambiciosa (GEALL; ELY, 2018).

$\mathrm{Na}$ conferência anual de 2016 do Conselho de Cooperação Internacional sobre Meio Ambiente e Desenvolvimento da China (CCICED, 2016), a tradição da cooperação Sul-Sul é destacada como um assunto a ser aprofundado dentro do marco da CE. Neste marco, a China enfatiza suas normas de respeito mútuo, soberania, liderança e independência dos outros Estados (VADELL et al., 2020).

O exemplo mais proeminente da atuação internacional chinesa no momento é a Iniciativa Cinturão e Rota (Belt and Road Initiative, BRI) por ser entendida como expressão do autoentendimento chinês que coloca o "Reino do Meio" (zhongguo 中国) no centro da economia mundial, conforme ficou situado tradicional e historicamente (CHEN; FAZILOV, 2018). As dimensões ambientais da estratégia ainda ficam em um segundo plano na BRI (ASCENÇÃO et al., 2018; MASOOD, 2019), mas há de se esperar que a CE, como ideia-guia pelas 
próximas décadas, também traga mudanças no que tange o cenário global da sustentabilidade (BANCO MUNDIAL, 2014; HART et al., 2017; HE; COUTO JR, 2019).

Com a CE, O PCC criou uma meta civilizatória utópica abrangente e aberta à interpretação pelos diferentes setores da administração pública e da sociedade, sendo colocada em prática no nível local em diversas áreas como educação, turismo, agricultura e setor imobiliário (SCHMITT, 2016). O discurso precedente do Modelo Chinês (Zhongguo moshi 中国模式), que, no nível internacional, era refletido pelo Consenso de Pequim (Beijing gongshi 北京共识), de acordo com Carrai (2018), teve suas origens no modelo revolucionário chinês dos anos 1960, quando a RPC tentava ativamente exportar o socialismo e apoiava movimentos comunistas em diferentes partes do mundo. Mesmo que muitas vezes negado pelo próprio governo chinês, o fato é que alguns países do Sul Global podem estar vendo o modelo chinês como exemplo a ser replicado, ou como influência para certos modos de governança pública. Existem indícios de que os jovens no Sul Global veem a China de forma mais positiva (SILVER et al., 2019), sendo evidente que, durante a pandemia da Covid-19, na qual o governo chinês investiu em uma "diplomacia de saúde", o modelo de governança chinesa atraiu mais interesse pelos países em desenvolvimento.

O aspecto relevante no discurso da CE são os países anteriormente não alinhados ao Consenso de Washington como modelos de economias liberais e democráticas. Rapoza (2013) sugere que os discursos do presidente Xi Jinping de 2014 enfatizaram a ideia de que não se deve mais avaliar o desempenho dos líderes só com base no crescimento do PIB de seus países; é necessário, em vez disso, considerar elementos como bem-estar, desenvolvimento social e indicadores ambientais. Essa mudança de discurso também se reflete nas instituições da esfera pública chinesa (BEESON, 2018; MU, 2018; HART, 2019).

A concomitante internalização da questão ambiental já aconteceu nas políticas chinesas em duas fases: entre 1992 e 2006 e, depois, de 2007 a 2012 (FERREIRA; BARBI, 2018). Nos anos 1990, estabeleceram-se importantes 
bases jurídicas, e os primeiros órgãos ambientais (existentes desde os anos 1980) foram consolidados. Essas mudanças foram majoritariamente respostas retóricas às críticas da comunidade internacional depois da Rio-92 (ibid.), pois já se registravam danos por poluição de águas e ar que custavam ao país entre $3,8 \%$ e $5,8 \%$ do seu PIB (BANCO MUNDIAL, 2007). Souza (2017) identifica o desenvolvimento energético na segunda fase de evolução das políticas ambientais chinesas, que, a partir do $12^{\circ}$ Plano Quinquenal (2011-15) passou a incorporar variáveis de sustentabilidade. Nessa época, o crescimento econômico chinês de dois dígitos começou a diminuir depois de três décadas, e a orientação da economia se voltou mais ao mercado doméstico (CASTRO, 2017). É possível perceber, então, uma preocupação mais séria com a questão energética, intimamente conectada com os problemas de poluição do ar, a qual começa a entrar em primeiro plano.

Os primeiros passos para a adoção de normas jurídicas concretas que discursivamente promovem, em um primeiro momento, um "progresso ecológico", foram dados em 2013, no $18^{\circ}$ Congresso Nacional do PCC. As "linhas vermelhas para a proteção ecológica" (shengtai baohu hongxian 生态保护红线) indicam uma terceira fase que concretiza a integração de instituições, direitos de propriedade a recursos naturais e mecanismos de compensação com base no princípio poluidor-pagador (KITAGAWA, 2017). Além disso, foram reformadas as controversas avaliações pela responsabilidade de cumprimento de objetivos ambientais, definidas localmente, que permitiam uma avaliação enviesada pelos governos locais (MU, 2018).

$\mathrm{Na}$ China contemporânea, a tensão entre propaganda e ciência é um fenômeno que existe pelo menos desde o Massacre de Tian'anmen em 1989 (WANG; KARL, 1998), influenciando amplamente debates domésticos e internacionais (CHEN, 2018). Pesquisas como as de Heike Holbig (2014) e Coraline Goron (2018) afirmam que a discussão sobre sustentabilidade na China e a produção científica relacionada se moldam aos discursos do Partido. A quantidade de artigos científicos publicados, especialmente em revistas econômicas e de estudos ambientais, que fazem uso do conceito guarda-chuva 
da CE, disparou de poucas dezenas em 2000 a mais de 6.400 em 2017. Goron (2018, p. 49) conclui que, ao mesmo tempo em que a ciência chinesa se engajou com debates globais sobre sustentabilidade, o contexto nacional observou a preparação de uma definição e teoria própria.

Mesmo com a queda nas taxas de crescimento econômico, muitas vezes julgadas como a única legitimadora do regime entendido por alguns, de forma superficial, como simplesmente autoritário, o governo possui apoio pela maior parte da população, devido ao caráter responsivo do seu autoritarismo (VAN ROOIJ et al., 2016). Apesar da falta de legitimidade democrática (no sentido Ocidental), o Partido transforma suas abordagens a partir da interação com a sociedade, exercendo mais autoritarismo a partir do governo central, mas sem deixar de incorporar boas práticas no nível local (de forma bottom-up) para incluir novos atores em áreas e atuações que não colocam em dúvida o poder do Estado (ZHONG; CHEN, 2013; BELL, 2015; BARBIERI, 2020).

\section{Novas normas para as políticas ambientais internacionais?}

Nesta seção, questionamos se tais ideias e discursos acerca de um modelo chinês de desenvolvimento mais "ecológico" se concretizam em uma abordagem, ou mesmo uma norma, de política mais "sustentável" em nível internacional, conforme liderança da China. Pode uma diretriz política nacional fazer com que outros países que se entendem como parte do mesmo "bloco", como os BRICS, G88, ou até mesmo o Sul Global inteiro, mudem seus interesses, modelos e prioridades de desenvolvimento em direção a modos de produção e de consumo mais sustentáveis? Destacam-se aqui, de forma muito breve, dois exemplos de normas e instituições chinesas cuja influência na governança ambiental global pode apresentar desempenho significante.

Instituições Internacionais "com características chinesas"?

Em nível internacional, a China tem atuado cada vez mais fortemente de acordo com sua crescente importância na economia global. O envolvimento comercial global a partir da BRI orienta uma grande estratégia de internacionalização, pela qual normas chinesas se propagam tanto na governança global (YU, 2019; COSTA, 2020) quanto em normas técnicas, como 
nos sistemas de avaliação ambiental, que podem ser mais amplamente difundidas por tal governança (TSIM et al., 2019).

Considerando as mudanças do sistema internacional nas quais há uma retração do poder relativo dos Estados Unidos e da Europa enquanto potências hegemônicas, e tendo em vista, também, a emergência de novos hegemons regionais, dentre os quais a China se destaca em um escopo cada vez mais global, cresce, por consequência, a importância de normas e instituições que são promovidas por estes novos atores. $\mathrm{Na}$ discussão sobre a questão ambiental, que ganhou foco central apenas nas últimas três décadas (FERREIRA, 2017), a emergência de um novo paradigma de sustentabilidade, diferenciado daqueles concordados multilateralmente nas conferências da ONU, ainda não é facilmente identificada.

A tendência da diplomacia internacional em buscar mais negociações bilaterais em vez de multilaterais é, também, uma preferência particular da China, como se observa em recentes negociações chinesas no G20, ou com membros individuais da União Europeia sobre a BRI (JAKÓBOWSKI, 2018). No entanto, entendendo que o papel da China no futuro próximo deve ser de maior economia do mundo, não se pode conduzir uma discussão acerca da ordem ambiental internacional sem considerar o significado da adoção de critérios ambientais como os discutidos no modelo chinês de desenvolvimento, em conjunto com a consistência e o planejamento de longo prazo do modelo de governança de partido único. É preciso considerar fortemente, nesta discussão, possíveis desenvolvimentos de novas normas e instituições.

Heilmann et al. (2014) apontam para o estabelecimento de instituições paralelas, através das quais a China vem construindo e difundindo novas normas deste tipo, além de identificar tais características como parte de uma espécie de "política externa de sombras" (shadow foreign policy). De acordo com estes autores, instituições como os BRICS, a Parceria Regional Econômica Abrangente (RCEP) e o Banco Asiático de Investimentos em Infraestrutura (AllB) consistem em estruturas paralelas que competem com as já existentes e hegemônicas. Sugere-se que essa abordagem chinesa possa ser vista como um 
enfraquecimento coordenado dos esforços da comunidade internacional liberal para integrar a China na ordem hegemônica existente. O engajamento pró-ativo em proposições de acordos de livre comércio como a RCEP e a Área de Livre Comércio da Ásia-Pacífico, podem evidenciar o posicionamento da China como uma espécie de empreendedora normativa na região da Ásia Oriental (HEILMANN et al., 2014). Por um lado, este tipo de argumentação promove, também, uma noção de ameaça chinesa, defendida pelos Estados Unidos para manter seus interesses hegemônicos na região da Ásia-Pacífico. Por outro lado, o foco em assuntos internos e a pouca diplomacia significativa com a Ásia faz com que o governo Trump conceda uma abertura para a China assumir seu papel de liderança regional.

Essas tendências de liderança chinesa com ideias próprias também estão ficando mais evidentes em organizações internacionais. $\mathrm{Na} O N U$, o país tem se mostrado mais ativo, e atualmente lidera quatro das 15 agências especializadas da instituição: a Organização de Aviação Civil Internacional; a União Internacional de Telecomunicações; a Organização para Alimentação e Agricultura (FAO); e a Organização de Desenvolvimento Industrial (UNIDO). No caso da FAO, o ex-vice-ministro chinês da agricultura, Qu Dongyu (屈冬玉), tomou posse no ano passado e apresentou uma possível mudança nas perspectivas da organização (SOUTAR, 2019). A China já é o maior contribuinte da UNIDO (19,7\% do orçamento total), da UNESCO (15,5\%) e da OMS (12\%), e o segundo maior contribuinte da FAO (12\%) e da OIT (12\%) (PINOTTI, 2020). Instituições como o Novo Banco de Desenvolvimento (NDB, também conhecido como Banco dos BRICS) têm mostrado diretrizes interessantes a se observar, priorizando créditos e investimentos com critérios que estão de acordo com diretrizes nacionais definidas pelos $12^{\circ}$ e $13^{\circ}$ Planos Quinquenais da China, que visam priorizar critérios de sustentabilidade. Além disso, os novos bancos do Sul Global, como o AllB e o NDB, já apresentam a questão ambiental como requisito para investimento nos projetos selecionados para a recuperação pós-Covid (AllB, 2020). 
Na liderança da FAO, o agrônomo Qu Dongyu, que assumiu o cargo em agosto de 2019, após trabalhar como vice-ministro de agricultura e assuntos rurais chineses, é reconhecido como "mais cauteloso quanto à visão dos EUA de grande agricultura e inovação biotecnológica para aumentar a produtividade das culturas". De acordo com Soutar (2019), o líder "tem o apoio de vários países da América Latina, especialmente o Brasil, a quem a China vem recorrendo cada vez mais por produtos agrícolas em meio às tensões comerciais com os EUA." $A$ posição de líderes e intelectuais chineses em altos cargos da ONU pode eventualmente contribuir com um maior reconhecimento da RPC e de suas normas como ator em prol do meio ambiente.

\section{Civilização Ecológica e Compensações}

A promulgação da CE como diretriz ideológica do PCC inicialmente não atraiu muita atenção acadêmica, mas na conjuntura atual está se mostrando cada vez mais importante (WANG-KAEDING, 2018). Hansen et al. (2018) descrevem este ideal como resposta do governo à degradação ambiental e como uma visão para um futuro global. Em linha com as questões instigadas pelos autores, queremos discutir nesta seção os possíveis valores e visões realmente implicados pela $\mathrm{CE}$.

A Construção da CE procura colocar "a China no centro do mapa do mundo ao invocar seus 2500 anos de herança filosófica tradicional como parte de uma solução para o futuro do planeta" (WANG-KAEDING, 2018, p. 196). O "imaginário sociotécnico [criado] integra valores culturais e morais com objetivos tecnológicos e políticos" (ibid.). Na 75a sessão da Assembléia Geral da ONU, em setembro de 2020, Xi Jinping reforçou novamente (e em contraste com a liderança estadunidense) que a China acredita em uma "comunidade com um futuro em comum" e que a "Covid-19 nos lembra que a humanidade deve lançar uma revolução verde" (TIEZZI, 2020; XI, 2020). Com o anúncio das metas sobre o pico de emissões em 2030 (meta 1) e acerca de se transformar em um país neutro em emissões de carbono até 2060 (meta 2), a China estabeleceu pontoschaves na construção de novas normas (HAAS, 2002) que definirão as discussões internacionais pós-pandemia (NORMILE, 2020; TOOZE, 2020). 
Antes disso, o país também mostrou que abandonou atitudes prejudiciais e trocou seu papel de "peso morto" na Conferência do Clima de Copenhague, em 2009, para o de um líder global do clima no Acordo de Paris (GAO, 2018).

O estabelecimento de metas ambiciosas não é surpreendente na política doméstica chinesa. No entanto, esse processo ganha uma nova dimensão com a expansão concomitante do país na arena internacional. É de grande relevância entender como as normas ambientais estabelecidas domesticamente pela China podem influenciar as agendas ambientais de outros países no mundo póspandemia. Em setembro de 2015, na Assembléia Geral da ONU, o Presidente Xi Jinping anunciou a criação do "Fundo de Cooperação Sul-Sul para a Mudança Climática", do "Fundo de Assistência à Cooperação Sul-Sul" e do "Instituto de Desenvolvimento da Cooperação Sul-Sul", todos focados na promoção da assistência à economia dos países em desenvolvimento (CCICED, 2016). Tais organizações, ao estabelecerem seus próprios critérios, apresentam formas de financiamento e execução técnica conforme definido pela China.

Um caso interessante para esta discussão diz respeito à conservação ambiental, que tem sido discutida dentro de um sistema de "compensações ecológicas" (eco-compensações) estabelecidas na RPC. O desenvolvimento das ferramentas de conservação se deu, em grande parte, com base nas experiências de outros países do Sul Global segundo o que é rotulado, como solução pelo mercado, por "Pagamento por Serviços Ambientais" (PSA). As ecocompensações foram integradas a experimentos locais e regionais de conservação antes da existência de uma política nacional consolidada (SCHOMERS; MATZDORF, 2013). Junto com o estabelecimento de um mecanismo permanente de monitoramento e alerta rápido para a capacidade de carga e de recursos (COMITÊ CENTRAL DO CPC DA RPC, 2017), a integração de indicadores e dados para colocar em prática uma economia mais sustentável avançou de forma pouco comparável com outros países (UNEP, 2016).

Antes do reconhecimento e da obrigatoriedade jurídica de mecanismos de compensação no planejamento econômico discutido acima (KITAGAWA, 2017), as amplas estratégias de conservação de bacias hidrográficas foram integradas 
a parques nacionais e áreas de alta importância ecológica (ZHANG; BENNETT, 2011). Devido às características geofísicas da China, que conta com amplas secas no Norte e alagamentos no Sul, os efeitos das mudanças climáticas sem estratégias de adaptação adequadas seriam muito graves (BANCO MUNDIAL, 2007; FERREIRA, 2017; TANG; GE, 2017).

De acordo com um estudo do Banco Asiático de Desenvolvimento (ADB, 2016), os investimentos em serviços de bacias hidrográficas, incluindo especialmente mecanismos de compensação como o pagamento por serviços ambientais, são os maiores do mundo. A RPC liderou a Ásia e o mundo em investimentos em bacias hidrográficas, tanto em termos de contagem de programas quanto em valores de transações. Com o gasto total do governo chegando a quase US $\$ 11,5$ bilhões em 2013 , os programas de compensação de bacias representaram $94 \%$ de todos os investimentos no mundo, e mais de 99\% de todos os pagamentos feitos na Ásia em serviços de bacias hidrográficas. Com mecanismos inovadores intra-provinciais, e mecanismos inter-provinciais para arranjos de compensação ecológica de bacias hidrográficas entre duas ou mais províncias, a China está liderando uma discussão que, em outras partes do mundo, ainda enfrenta gargalos institucionais e jurídicos significativos (SHANG et al., 2018).

Combinando-se com o destaque da Civilização Ecológica como fenômeno particular expresso em elementos culturais e na relação Estado-sociedade, a discussão ambiental já evidencia abordagens diferenciadas que podem ser entendidas como uma mudança de norma. Com base nas ideias de Haas (1992) sobre comunidades epistêmicas, as políticas de eco-compensação podem ser pensadas como uma própria comunidade epistêmica chinesa sob direcionamento do PCC, que reinterpreta normas estabelecidas pelos experts ocidentais e as reconfigura de acordo com o planejamento nacional. Assim, a "redefinição de interesses preconcebidos" e a "definição de novo interesse" do Estados a partir de comunidades de experts em um dado contexto diferenciado de relações de poder internacional, podem ser observadas no surgimento das eco-compensações que se diferenciam do PSA ocidental, iniciando uma 
mudança de paradigma na literatura global sobre PSA e marcando a transformação de norma descrita nesse artigo (SCHOMERS; MATZDORF, 2013; CHEN et al., 2020; YU et al., 2020).

Outro indício pode ser apontado a partir da presença de fomentos chineses à pesquisa em áreas estratégicas da BRI que atraem jovens comerciantes, obreiros e acadêmicos. Desta forma, de acordo com Ehsan Masood (2019), a China já está "'redesenhando os mapas' da ciência global" por meio de bolsas de estudo e perspectivas laborais na cooperação que permitiria aos cientistas selecionados levarem os conhecimentos diferenciados de volta aos seus países, modificando abordagens nacionais a partir da experiência chinesa.

\section{Considerações Finais}

Este artigo se propôs a discutir as eventuais mudanças sobre novas normas na política ambiental internacional decorrentes do plano da "Construção de uma Civilização Ecológica" na China. Com base na exploração da trajetória chinesa pelo equilíbrio entre crescimento industrial-econômico e preocupações ambientais, a CE propõe um novo tipo de cultura no nível retórico, com ainda pouca materialização visível. Porém, tendo em vista as instituições recentemente criadas e as normas que estão se desenvolvendo cada vez mais claramente, há indícios que podem, no futuro, trazer mudanças para a forma como se aborda a política ambiental.

Observou-se que a crescente autoconfiança agregada ao sistema de governança chinês torna possível, e necessário, não só adequar, como também redefinir, concepções de desenvolvimento expressas em políticas de conservação. Considerando indicadores econômicos e recentes de melhorias na qualidade do ar, as mudanças jurídicas encadeadas com o projeto não aparentam ser meramente promessas políticas vazias, conforme colocado por alguns autores (GORON, 2018). Através de uma abordagem totalitária e autoritária, consegue-se um cumprimento rígido das diretivas centrais quando estas são colocadas como prioridade política (BEESON, 2018). Contudo, além 
das implicações internacionais, essas mudanças radicais têm interessantes consequências no nível local, onde ainda se devem provar como geradoras de uma profunda mudança de paradigma em direção a uma cultura realmente mais sustentável em todos os âmbitos no pós-pandemia.

A atuação da RPC na adaptação às mudanças climáticas e sua elaboração de novas abordagens foi discutida muito resumidamente aqui, e merece mais aprofundamento para que se entendam as nuances que perpassam essa atuação. Vale lembrar que, mesmo sendo um regime de partido único, os grupos de interesse na China estão em um processo de pluralização, de forma que mecanismos de participação demonstram complexas disputas entre o governo central e as diferentes unidades territoriais que agem como atores políticos, tais quais províncias, regiões autônomas e, principalmente, cidades (SHAMBAUGH, 2013; BELL, 2015; BARBIERI, 2020). De um ponto de vista estratégico, é discutível se as instituições chinesas seguem uma visão única e clara para definir padrões novos ou paralelos que desafiam as existentes, e se consistem em um tipo de empreendedorismo normativo (HEILMANN et al., 2014; WEINS, 2015). Pensando na replicabilidade do modelo chinês para outros países, Castro (2017, p. 79) lembra que "cada experiência ou via de desenvolvimento é única" e que "o caso chinês é um dos menos replicáveis do planeta". No entanto, o estudo de caso chinês pode trazer uma reflexão sobre políticas de Estado que precisam ser inseridas em um projeto nacional para uma permanência necessária de políticas de sustentabilidade e instituições duradouras que defendam o ambiente contra interesses econômicos míopes.

O futuro de instituições como o Banco dos BRICS, o AllB e os mecanismos ligados à $\mathrm{BRI}$ será um definidor importante de interesses estratégicos chineses na difusão de novas normas. O caso das compensações ecológicas, mesmo embutidas em um contexto jurídico e econômico muito específico (devido aos grandes investimentos e à crescente popularidade de tais ferramentas) podem fazer com que a China seja uma referência para a execução de projetos, e, eventualmente, um exemplo em investimentos 
internacionais destinados a mitigar externalidades globais do consumo da crescente classe média chinesa (WEINS et al., 2019).

\section{Referências}

ADB - ASIAN DEVELOPMENT BANK. Toward a National Eco-compensation Regulation in the People's Republic of China. Manila: Asian Development Bank. 2016. Disponível em: https://www.adb.org/sites/default/files/publication/212726/ecocompensation-regulation-prc.pdf.

AllB - Asian Infrastructure Investment Bank. AllB and Amundi Launch Climate Change Investment Framework to Drive Asia's Green Recovery and Transition the Paris Agreement. Beijing: AllB. 2020. Disponível em: https://www.aiib.org/en/newsevents/news/2020/AIIB-and-Amundi-Launch-Climate-Change-Investment-Framework-toDrive-Asia-Green-Recovery-and-Transition.html.

ASCENÇÃO, F.; FAHRIG, L.; CLEVENGER, A. P.; CORLETT, R. T.; JAEGER, J. A. G.; LAURANCE, W. F.; PEREIRA, H. M. Environmental challenges for the Belt and Road Initiative. Nature Sustainability, v. 1, n. 5, p. 206-209, 15 maio 2018. Disponível em: http://www.nature.com/articles/s41893-018-0059-3.

AUTH, G. Theorien der Internationalen Beziehungen kompakt. Berlin: Oldenbourg Wissenschaftsverlag, 2015. http://doi.org/10.1524/9783486711219.

BANCO MUNDIAL. Cost of pollution in China - economic estimates of physical damages. p. 151. Washington D.C.: The World Bank. 2007.

BANCO MUNDIAL. Implications of a changing China for Brazil: a new window of opportunity? p. 132. Washington D.C.: The World Bank. 2014.

BARBI, F.; FERREIRA, L. C.; GUO, S. Climate change challenges and China's response: mitigation and governance. Journal of Chinese Governance, v. 1, n. 2, p. 324-339, 2016. https://doi.org/10.1080/23812346.2016.1181598.

BARBIERI, M. D. Sociedade civil, Estado e questão ambiental na China. 2020. Universidade Estadual de Campinas, 2020. Tese de doutorado. Disponível em: http://repositorio.unicamp.br/jspui/handle/REPOSIP/342031.

BEESON, M. Coming to Terms with the Authoritarian Alternative: The Implications and Motivations of China's Environmental Policies. Asia \& the Pacific Policy Studies, v. 5, n. 1, p. 34-46, jan. 2018. Disponível em: http://doi.wiley.com/10.1002/app5.217.

BELL, D. A. The China Model: Political Meritocracy and the Limits of Democracy. Princeton: Princeton University Press. 2015.

CARRAI, M. A. In the Eye of the Beholder: The China Model as a discourse. Fairbank Center Blog, 2018. Disponível em: https://medium.com/fairbank-center/in-the-eye-ofthe-beholder-the-china-model-as-a-discourse-fbf95e06361c. 
CASTRO, D. China a as conexões do desenvolvimento: Questões e economia, sociedade e política. Revista Tempo do Mundo, v. 3, n. 2, p. 37-82, 2017. Disponível em: http://repositorio.ipea.gov.br/handle/11058/8211.

CCICED. South-South Cooperation for Ecological Civilization (Draft). Beijing: China Council for International Cooperation on Environment and Development. 2016. Disponível em: https://www.die-gdi.de/uploads/media/CCICED-south-south-cooperationfor-ecological-civilization-final-1125.pdf.

CHAN, G.; LEE, P. K.; CHAN, L.-H. China Engages Global Governance. a new world order in the making?. Routledge, 2011. Disponível em: http://doi.org/10.4324/9780203698334.

CHEN, C.; MATZDORF, B.; ZHEN, L.; SCHRÖTER, B. Social-Network Analysis of local governance models for China's eco-compensation program. Ecosystem Services, v. 45, n. April, p. 101191, out. 2020. Disponível em: https://doi.org/10.1016/j.ecoser.2020.101191.

CHEN, H. F. Chinese Sociology: State-Building and the Institutionalization of Globally Circulated Knowledge. London: Macmillan, 2018. Disponível em: http://doi.org/10.1057/978-1-137-58220-1.

CHEN, X.; FAZILOV, F. Re-centering Central Asia: China's "New Great Game" in the old Eurasian Heartland. Palgrave Communications, v. 4, n. 1, 2018. Disponível em: http://dx.doi.org/10.1057/s41599-018-0125-5.

COMITÊ CENTRAL DO CPC DA RPC. Várias Opiniões sobre o Estabelecimento de um Mecanismo Eficaz de Longo Prazo para Monitoramento e Alerta Antecipado de Recursos e Capacidade de Carga Ambiental 2017. Disponível em: http://www.pkulaw.cn/fulltext_form.aspx?Db=chl\&Gid=302186.

COPELAND, D. C. The Constructivist Challenge to Structural Realism: A Review Essay. International Security, v. 25, n. 2, p. 187-212, out. 2000. Disponível em: https://www.mitpressjournals.org/doi/abs/10.1162/016228800560499.

COSTA, C. M. The Words of the Belt and Road Initiative: A Chinese Discourse for the World? In: LEANDRO; DUARTE. The Belt and Road Initiative. Singapore: Springer Singapore, 2020. p. 23-44. Disponível em: http://doi.org/10.1007/978-981-15-2564-3_2.

EATON, S.; KOSTKA, G. Authoritarian environmentalism undermined? Local leaders' time horizons and environmental policy implementation in China. China Quarterly, v. 218, n. 1, p. 359-380, 2014. Disponível em: https://doi.org/10.1017/S0305741014000356.

EBERHARD, J. W. Socialized or Calculated Interests. Analysing China's Regional Policy through Constructivist and Rationalist Perspectives. Georgia State University, 2008.

FINNEMORE, M.; SIKKINK, K. International Norm Dynamics and Political Change. International Organization, v. 52, n. 4, p. 887-917, 1998. Disponível em: https://www.jstor.org/stable/2601361\%0A. 
FERREIRA, L. C. O Desafio das Mudanças Climáticas: Os Casos Brasil e China. Jundiaí: Paco, 2017.

FERREIRA, L. C.; BARBI, F. Governing climate change in China and Brazil: empirical studies. In: FERREIRA, L. C. (Ed.). The sociology of environmental issues: theoretical and empirical investigations. Curitiba: CRV, 2018. p. 135-154.

GAO, X. China's Evolving Image in International Climate Negotiation: From Copenhagen to Paris. China Quarterly of International Strategic Studies, v. 04, n. 02, p. 213-239, 2018. Disponível em: https://doi.org/10.1142/S2377740018500112.

GEALL, S.; ELY, A. Narratives and Pathways towards an Ecological Civilization in Contemporary China. The China Quarterly, v. 236, p. 1175-1196, 2018. Disponível em: https://doi.org/10.1017/S0305741018001315/.

GIDDENS, A. The politics of Climate Change. Cambridge: Polity Press, 2007.

GLOSNY, M. A. China and the BRICs: A Real (but Limited) Partnership in a Unipolar World. Polity, v. 42, n. 1, p. 100-129, jan. 2010. Disponível em: https://doi.org/10.1057/pol.2009.14.

GORON, C. Ecological Civilisation and the Political Limits of a Chinese Concept of Sustainability. China Perspectives, v. 2018, n. 4, p. 39-52, 31 dez. 2018. Disponível em: http://journals.openedition.org/chinaperspectives/8463.

GOTTWALD, J. C.; DUGGAN, N. Expectations and adaptation: China's foreign policies in a changing global environment. International Journal of China Studies, v. 2, n. 1, p. 1-26, 2011.

GROSSMAN, D. China's aggression amid the COVID-19 pandemic has little to do with COVID-19. World Politics Review, v. May, n. 20, 2020.

HAAS, P. M. Introduction: epistemic communities and international policy coordination. International Organization, v. 46, n. 01, p. 1, 1992. Disponível em: http://www.journals.cambridge.org/abstract_S0020818300001442.

HAAS, P. M. UN conferences and constructivist governance of the environment. Global governance, v. 8, p. 73, 2002.

HANSEN, M. H.; LI, H.; SVARVERUD, R. Ecological civilization: Interpreting the Chinese past, projecting the global future. Global Environmental Change, v. 53, n. April, p. 195-203, nov. 2018. Disponível em: https://doi.org/10.1016/j.gloenvcha.2018.09.014.

HANSON, A. Ecological Civilization in the People's Republic of China: Values, Action, and Future Needs. ADB East Asia Working Paper Series, n. 21, 2019. Disponível em: https://www.adb.org/publications/ecological-civilization-values-action-future-needs.

HART, C. A. From Paris to Beijing: Implementing the Paris Agreement in the People's Republic of China. Washington D.C.: Atlantic Council. 2019. 
HART, C.; JIAYAN, Z.; JIAHUI, Y. Mapping China's Climate Policies. 2017. Disponível em: http://www.chinacarbon.info.

HE, N.; COUTO JR, F. Can Brazil replicate China's successful solar industry? London: Diálogo Chino / Instituto Clima e Sociedade. 2019.

HEILMANN, B. S.; RUDOLF, M.; HUOTARI, M.; BUCKOW, J. China's Shadow Foreign Policy: Parallel Structures Challenge the Established International Order. Mercator Institute for China Studies (Merics), v. 18, p. 1-9, 2014.

HOLBIG, H. Shifting Ideologies of Research Funding: The CPC's National Planning Office for Philosophy and Social Sciences. Journal of Current Chinese Affairs, v. 43, n. 2, p. 13-32, jun. 2014.2 Disponível em: http://journals.sagepub.com/doi/10.1177/186810261404300203.

JAKÓBOWSKI, J. Chinese-led Regional Multilateralism in Central and Eastern Europe, Africa and Latin America: $16+1$, FOCAC, and CCF. Journal of Contemporary China, v. $27, \quad$ n. $113, \quad$ p. $659-673,3$ set. 2018. Disponível em: https://doi.org/10.1080/10670564.2018.1458055.

JONES, C. Contesting within order? China, socialisation, and international practice. Cambridge Review of International Affairs, v. 33, n. 1, p. 105-133, 2 jan. 2020. Disponível em: https://www.tandfonline.com/doi/full/10.1080/09557571.2019.1674781.

KITAGAWA, H. Environmental Policy Under President Xi Jinping Leadership: The Changing Environmental Norms. Chap. 1. In: KITAGAWA, H. (Ed.). Environmental Policy and Governance in China. Springer, Tokyo. https://doi.org/10.1007/978-4-43156490-4.

KLEIN, N. This Changes Everything: Capitalism vs. the Climate. London: Penguin. 2014.

LAHIRI-DUTT, K. Living in, and thinking about, the world in pandemic times. Ecology, Economy and Society - the INSEE Journal, v. 3, n. 2, p. 1-3, 2020. Disponível em: https://ecoinsee.org/journal/ojs/index.php/ees/article/view/283.

MA T.; LIU Q. China reshapes ministries to better protect environment. China Dialogue. 2018. p. 2-5. Publicado em 14/03/2018. Disponível em: https://www.chinadialogue.net/article/China-reshapes-ministries-environment.

MARINELLI, M. How to Build a 'Beautiful China' in the Anthropocene. The Political Discourse and the Intellectual Debate on Ecological Civilization. Journal of Chinese Political Science, v. 23, n. 3, p. 365-386, 22 set. 2018. Disponível em: http://doi.org/10.1007/s11366-018-9538-7.

MARSHALL, G.; SCOTT, J. A Dictionary of Sociology. 3 rev. ed. Oxford: Oxford University Press. 2009. 
MASOOD, E. How China is redrawing the map of world science. Nature, v. 569, n. 7754, p. 20-23, 1 maio 2019. Disponível em: http://www.nature.com/articles/d41586-01901124-7.

MINZER, C. The Rise of China and the Interests of the United States. The Ripon Forum, v. 41. n. 2. 2007.

MU, R. Bounded Rationality in the Developmental Trajectory of Environmental Target Policy in China, 1972-2016. Sustainability, v. 10, n. 1, p. 199, 2018. Disponível em: http://doi.org/10.3390/su10010199.

NORMILE, D. Can China, the world's biggest coal consumer, become carbon neutral by 2060? Science, 29 set. 2020. Disponível em: https://doi.org/10.1126/science.abf0377.

PAN, Y. (潘岳). Sobre uma civilização ecológica socialista (Lun shehui zhuyi shengtai wenming 论社会主义生态文明). Green Leaf (Iüdie 绿叶), v. 10, p. 10-18. 2006.

PINOTTI, T. de M. A participação chinesa na ONU: de espectadora à protagonista. In: Anais do $4^{\circ}$ Seminário Pesquisar China Contemporânea. Campinas: Editora da Unicamp, $2020 . \quad$ Disponível em: https://econtents.bc.unicamp.br/eventos/index.php/chinabrasil/issue/archive.

RAPOZA, K. China's Pres Xi: GDP No Longer The Measure Of Success. Forbes, 1 jul. 2013. Disponível em: https://www.forbes.com/sites/kenrapoza/2013/07/01/chinas-presxi-gdp-no-longer-the-measure-of-success/\#35f4149b18db.

RIBEIRO, W. C. A ordem ambiental internacional. Editora Contexto, 2001.

SCHMITT, E. A. The Atmosphere of an Ecological Civilization: A Study of Ideology, Perception and Action in Chengdu, China. The Chinese University of Hong Kong. Tese de doutorado. 2016.

SCHOMERS, S.; MATZDORF, B. Payments for ecosystem services: A review and comparison of developing and industrialized countries. Ecosystem Services, v. 6, p. 16-30, 2013.

SHAMBAUGH, D. China Goes Global - The Partial Power. Cambridge: Oxford University Press, 2013.

SHANG, W.; GONG, Y.; WANG, Z.; STEWARDSON, M. J. Eco-compensation in China: Theory, practices and suggestions for the future. Journal of Environmental Management, v. 210, p. 162-170, mar. 2018. Disponível em: https://doi/org/S0301479717312653.

SILVER, L.; DEVLIN, K.; HUANG, C. People around the globe are divided in their opinions of China. Washington D.C.: Pew Research Center. 2019. Disponível em: https://pewrsr.ch/2IJHUr6.

SOUTAR, R. World food systems at a critical juncture ahead of Rome summit. Diálogo Chino. 21/5/2019. 
SOUZA, L. E. V. A internalização paradoxal dos critérios de sustentabilidade na formulação das estratégias de China e Brasil para o setor energético. In: FERREIRA, L. C. (Org.). O desafio das mudanças climáticas: os casos Brasil e China. Jundiaí: Paco, 2017, Cap. 6, p. 167-192.

TANG, Q.; GE, Q. (Ed). Atlas of environmental risks facing China under climate change. Springer, 2017. http://doi.org/10.1007/978-981-10-4199-0.

TIEZZI, S. At UN, Xi Outlines China's Vision for the World. The Diplomat, v. Sept, n. 23, 2020. Disponível em: https://thediplomat.com/2020/09/at-un-xi-outlines-chinas-vision-forthe-world/.

TOOZE, A. Did Xi Just Save the World? Foreign Policy, Sept, n. 25, 2020.

TSIM, S.; SU, S. Y.; YUEN, B. B.; XIE, M. L. Comparison of Building Environment Assessment Systems Across the Belt and Road Countries: How Do Green Buildings Contribute to Achieving Ecological Civilization and Sustainable Development Goals? In: Silk Road to Belt Road. Singapore: Springer Singapore, 2019. p. 235-258. http://doi.org/10.1007/978-981-13-2998-2_14.

UNEP - Programa das Nações Unidas para o Meio Ambiente. Green is Gold: The Strategy and Actions of China's Ecological Civilization. 2016. Disponível em: http://reliefweb.int/report/china/green-gold-strategy-and-actions-china-s-ecologicalcivilization.

VADELL, J.; BRUTTO, G. Lo; LEITE, A. C. C. The Chinese South-South development cooperation: an assessment of its structural transformation. Revista Brasileira de Política Internacional, v. 63, n. 2, 2020. Disponível em: https://doi.org/10.1590/00347329202000201.

VAN ROOIJ, B.; STERN, R. E.; FÜRST, K. The authoritarian logic of regulatory pluralism: Understanding China's new environmental actors. Regulation \& Governance, v. 10, n. 1, p. 3-13, mar. 2016. Disponível em: https://doi.org/10.1111/rego.12074.

WANG-KAEDING, H. What does Xi Jinping's new phrase "Ecological Civilization" mean? An investigation of the phrase is pressing. The Diplomat, p. 1-6, 2018. Disponível em: https://thediplomat.com/2018/03/what-does-xi-jinpings-new-phrase-ecologicalcivilization-mean/.

WANG, H.; KARL, R. E. Contemporary Chinese Thought and the Question of Modernity. Social Text, n. 55, p. 9, 1998. Disponível em: https://www.jstor.org/stable/466684.

WEINS, N. W.; SCHMIDT, A. F. J.; HASE-UETA, M.; TJONG, E. Virtual Water in Commodity Trade between China and Brazil: new perspectives for a sustainable business environment? 3rd Annual Meeting Fudan Latin-America University Consortium. Santiago de Chile. 2019. 
WEINS, N. W. A constructivist perspective on the rise of China: a case of regional norm entrepreneurship?. Bachelor's thesis. Instituto de Estudos da Ruhr Universität Bochum. 2015.

WENDT, A. Anarchy is what states make of it: the social construction of power politics. International Organization, v. 46. n. 2. 1992. p. 391-425.

WENDT, A. Social Theory of International Politics. Cambridge: Cambridge University Press. 1999.

XI, J. Full text: Xi Jinping's speech at the General Debate of the 75th session of the United Nations General Assembly. CGTN, 2020. Discurso. Disponível em: https://news.cgtn.com/news/2020-09-23/Full-text-Xi-Jinping-s-speech-at-General-

Debate-of-UNGA-U07X2dn8Ag/index.html.

YU, B. Between Chinese and Western Norms: Local Policy Deliberation and Crossissue-area Variations in China's Global Governance Strategies. 2019. University of Toronto, 2019. Disponível em: https://tspace.library.utoronto.ca/bitstream/1807/97744/3/Yu_Bowen_201911_PhD_thesi s.pdf.

YU, H.; XIE, W.; YANG, L.; DU, A.; ALMEIDA, C. M. V. B.; WANG, Y. From payments for ecosystem services to eco-compensation: Conceptual change or paradigm shift? Science of the Total Environment, v. 700, p. 134627, 2020. Disponível em: https://doi.org/10.1016/j.scitotenv.2019.134627.

ZAGO, L. A questão ambiental na China de Mao Zedong e Deng Xiaoping. In: FERREIRA, L. C. (Org.). O desafio das mudanças climáticas: os casos Brasil e China. Jundiaí: Paco, 2017, Cap. 3, p. 83-110.

ZHANG, Q.; BENNETT, M. T. Eco-Compensation for Watershed Services in the People's Republic of China. Manila: Asian Development Bank, 2011.

ZHONG Y.; CHEN, Y. Regime Support in Urban China. Asian Survey, v. 53, n. 2, p. 369-92. 2013.

\section{NOTAS DE AUTOR}

\section{CONTRIBUIÇÃO DE AUTORIA}

Niklas Werner Weins - Concepção, Coleta de dados, Análise de dados, Elaboração do manuscrito, revisão e aprovação da versão final do trabalho.

Leila da Costa Ferreira - Concepção, revisão e aprovação da versão final do trabalho.

Rita de Cassia Oliveira Feodrippe Participação ativa da discussão dos resultados, revisão e aprovação da versão final do trabalho.

\section{FINANCIAMENTO}

Agradeçemos à Fundação de Amparo à Pesquisa do Estado de São Paulo (FAPESP) pelo funcionamento dos processos 19/03581-0, 17/06347-3 e 19/17490-7 e à Coordenação de Aperfeiçoamento de Pessoal de Nível Superior (CAPES) para o financiamento do processo 88887.356469/2019-00 que possibilitaram essa pesquisa. 
APROVAÇÃO DE COMITÊ DE ÉTICA EM PESQUISA

Não se aplica.

CONFLITO DE INTERESSES

Não há conflito de interesses.

\section{LICENÇA DE USO}

Este artigo está licenciado sob a Licença Creative Commons CC-BY. Com essa licença você pode compartilhar, adaptar, criar para qualquer fim, desde que atribua a autoria da obra.

\section{HISTÓRICO}

Recebido em: 30-9-2020

Aprovado em: 15-10-2020 